Dokuz Eylül Üniversitesi-Mühendislik Fakültesi Fen ve Mühendislik Dergisi

Cilt 20, Sayı 58, Ocak, 2018
Dokuz Eylul University-Faculty of Engineering Journal of Science and Engineering Volume 20, Issue 58, January, 2018

DOI: $10.21205 /$ deufmd. 2018205807

\title{
Önem Tahminleme Tabanlı Tek Sınıf Sınıflayıcı ile Doku Tanıma
}

\author{
Gökhan TIĞILSEL1, Güleser Kalaycı DEMiR*2 \\ ${ }^{1}$ Dokuz Eylül Üniversitesi, Fen Bilimleri Enstitüsü, İzmir (ORCID: 0000-0003-3722- \\ 3067) \\ ${ }^{2}$ Dokuz Eylül Üniversitesi, Mühendislik Fakültesi, Elektrik ve Elektronik Mühendisliği \\ Bölümü, İzmir (ORCID: 0000-0003-3808-5305)
}

(Alınış / Received: 23.01.2017, Kabul / Accepted: 28.09.2017, Online Yayınlanma / Published Online: 20.01.2018)

Anahtar Kelimeler Özet: Tek Sınıf Sınıflayıcı (TSS) ile doku tanıma, farklı sınıflara ait Önem Tahminleme, dokular içinde sadece ilgilenilen hedef dokuya ilişkin eğitim Yoğunluk Dağılım, verileri ile hedef dokunun tanınması problemidir. Bu çalışmada, Tek Sinif Sinıflayıc1,Doku Tanıma önem değerinin tahminlenmesine dayanan bir doku sinıflayıcı önerilmiștir. Önem değeri, test ve eğitim verilerinden elde edilen yoğunluk fonksiyonlarının oranından hesap edilmiştir. Girilen test verisi ile hedef sınıf verisi birbirine benzer ise önem değeri bire yakın olduğundan elde edilen önem değerlerine eşikleme işlemi uygulanarak sınıflama işlemi gerçeklenmiştir. Önem değeri, Kısıtsız En Küçük Kareler Önem Uydurma (KEKK-ÖU) yöntemi ile elde edilmiştir. Önerilen yöntemin etkinliği, farklı doku setleri üzerinde farklı sınıflama ölçütleri ile değerlendirilmiştir. Elde edilen sonuçlar önerilen yöntemin TSS problemlerinde başarılı ve güvenilir olduğunu göstermektedir. Sonuçlar, ayrıca literatürde referans yöntem olarak alınan tek-sınıf destek vektör makinaları yöntemine göre de karşılaştırılmış ve önerilen yöntem ile daha yüksek TSS başarım performansı elde edilmiştir.

\section{Texture Recognition Using Importance Based One-Class Classifier}

\begin{tabular}{ll}
\hline Keywords & Abstract: Texture recognition by Single-Class Classifier (SCC) \\
Importance & refers to the problem of recognizing the target texture by using only \\
Estimation, & the training data pertaining to the texture under concern. In this \\
Density & study, a texture classifier, based on the estimation of importance, \\
Distribution, & is proposed. Importance is calculated as the ratio of two density \\
One Class & functions obtained from the training and test data. Since the \\
Classification, & importance value is close to the one if the inputted test and target \\
Texture & class data are similar to each other, classification is performed by \\
Recognition & appliying a thresholding process to the obtained importance \\
& values. Importance is estimated by Unconstrained Least Square \\
& Importance Fitting (uLSIF) algorithm. The effectiveness of the \\
proposed method is examined on different texture sets with \\
different classification metrics. Our results show that the proposed
\end{tabular}


algorithm is powerful and reliable in SCC problems. Results are also compared with the one-class support vector machines which is the reference algorithm in the literature and higher SCC performance is obtained with the proposed method for applied textures .

*Sorumlu yazar: Güleser Kalaycı DEMiR e-mail: guleser.kalayci@deu.edu.tr

\section{Giriş}

Tek-Sınıf Sınıflayıcı (TSS) probleminde hedef sınıfa ilișkin nesnelerin farklı sınıflara ait nesneler içinde bulunması amaçlanmaktadır ve bu amaç için sadece hedef sınıfa ilişkin eğitim verilerinin kullanımı mümkündür.[1]. Sadece hedef sınıfa ait eğitim seti kullanıldı̆̆ından ve diğer sınıflara ilişkin veri bulunmadığından dolayı sınıflayıcının karar sinırları sadece bir yönden belirlenebilmektedir. Bu nedenle bitişik sınıflara ait tüm eğitim verilerini kullanarak karar sınırlarını olușturan çok-sınıf sınıflayıcılardan daha farklı ve daha zor bir problemdir. Yazında, izinsiz giriș tespiti [2], imza doğrulama [3] ve değișim tespiti [4] gibi farklı uygulama alanlarında son zamanlarda sıklıkla kullanılagelmektedir.

Bu tür uygulamalarda genellikle bir sınıfa ait örnek veri sayısı fazla olmakla birlikte diğer sınıflara ait örnek verilerin elde edilmesi çok zor veya pahalıdır. $\mathrm{Bu}$ duruma bir örnek olarak makine arızalarının bulunması problemi verilebilir [5]. $\mathrm{Bu}$ problemde, sınıflayıcının, normal (hedef sınıf) veya hatalı makine çalıșmasını tespit etmesi beklenmektedir. Makinenin normal çalıştığı durumlara ait örnekler (hedef sınıf eğitim verisi), rahatlıkla elde edilebilmekle birlikte, hatalı çalıșma durumlarına ilişkin örnekler (aykırı değerler) ya hiç ya da çok çok az elde edilebilmektedir. Çok fazla sayıda saklanmış görüntü içinde belli bir görüntünün bulunması problemi bir bașka örnek olarak verilebilir. Burada, istenen görüntüye ait bazı öznitelikler biliniyorken bu özniteliklere sahip olmayan tüm görüntülerin elimine edilmesi amaçlanmaktadır $\quad[6,7]$. Bu çalışmada da benzer bir problem üzerine çalıșlacak ve özgün bir yaklașım kullanılarak TSS ile sadece hedef dokuyu içeren alanlar tüm görüntü içinde bulunacaktır.

Genel olarak doku sınıflaması, görüntü içinde yer alan farklı dokuların hangi sınıfa ait olduğunu bulmayla ilgilenir. Yazında, bu tür problem için önerilmiș çok fazla sayıda çok-sınıf sınıflayıcı yöntemleri bulunmaktadır. [8-10]. Bu çalışmalardan çoğu Gri Seviye Birliktelik Matrisi (GSBM), Gabor ve Dalgacık öznitelikleri gibi öznitelik setlerinin kullanılmasına dayanmaktadır. Amaç, çok-boyutlu uzayda farklı sınıfları temsil eden bölgelerin belirlenmesi ve test verisi ile ilişkilendirilen bölgeye göre çok-sınıf sınıflama yapılmasıdır. $\mathrm{Bu}$ çalışmada, sadece ilgilenilen hedef dokuya ilişkin eğitim verileri olduğundan, bir başka deyişle dış sınırları belirleyen negatif örnekler olmadığından çok-sınıf sınıflayıcı yaklașımları uygulanabilir değildir. Yazında, Tek-sınıf Destek Vektör Makineleri (TS-DVM) [11], başarım performansı ile sık tercih edilen bir yöntem olarak ön plana çıkmaktadır [2,5,12]. [13] 'de bu yöntem doku sınıflaması problemine uygulanmıştır. TSDVM'in çözümü, aykırı değer oranı ve kullanılan Gauss çekirdek genişliği gibi parametre değerlerine bağlıdır. $\mathrm{Bu}$ parametrelerin seçilmesi için sistematik bir yöntem bulunmamakta ve elle deneyerek ayarlama gerçekleștirildiğinden dolayı öznel ve daha az güvenilirdir. [6]'de ise aynı probleme çok-katmanlı yapay sinir ağları modeli kullanımı ile yaklaşılmıştır. Tek sınıf sınıflayıcı problemi için yazında yoğunluk tabanlı yaklaşımlar da sıklıkla kullanılagelmiștir. Genellikle bu tür yöntemlerde, incelenen veri noktasının yakın çevresinde bulunan diğer verilerin 
sıklığ veya seyrekliğine göre karar verilmektedir ve performans, veri boyutunun artması ile ciddi anlamda düşebilmektedir $[14,15]$. Bu çalışmada daha farklı bir yaklaşım kullanılacak ve yoğunluk dağllım tahminlemesi yerine ilgilenilen veri ve yakın komşu verilerinin dağılım fonksiyonunun hedef sınıf dağılım fonksiyonuna ne kadar benzeștiği araştırılarak sonuca ulaşılacaktır. Benzeşme kriteri olarak test verisine ilişkin yoğunluk fonksiyonunun, eğitim verisi yoğunluk fonksiyonuna oranı (önem) önerilmiștir. Bildiğimiz kadarı ile bu tür bir yaklaşım, tek sınıf doku sınıflamasında daha önce kullanılmamıștır. Önem değerinin hesaplanmasında yüksek boyutlarda ayrı ayrı yoğunluk dağılımlarının hesaplanmasından kaçınan ve parametre seçimlerini sistematik olarak hesaplayabilen Kısıtsız En Küçük Kareler Önem Uydurma (KEKK-ÖU) yöntemi tercih edilmiştir [16].

\section{2. Önerilen Yöntem}

\subsection{Genel yapı}

$\mathrm{Bu}$ çalışmada, hedef ve test verisi yoğunluk fonksiyonlarının oranından elde edilen önem değeri sınıflama için kullanılacaktır. Önerilen yöntemin çıkış noktası, test dokusunun hedef dokuya olan benzerliğinin artması ile yoğunluk fonksiyonlarının benzerliklerinin de artması ve iki yoğunluk fonksiyonu arasındaki oranın bire yaklaşacağının dikkate alınmasıdır. Test verisi, hedef sınıftan ayrıldıkça önem değeri, 1 değerinden uzaklaşacaktır. Bu doğrultuda, öncelikle hedef dokunun öznitelikleri kullanılarak eğitim seti oluşturulmuştur. Daha sonra test verisinin öznitelikleri hesaplanmış ve önem tahminlemesinde bulunulmuştur. Elde edilen önem değerleri üzerinde eşikleme işlemi yapılarak sınıflama işlemi gerçekleştirilmiştir.

\subsection{Doku Öznitelik Seti}

$\mathrm{Bu}$ çalışmada doku tespiti amacı ile istatistiksel özniteliklerden faydalanılmıştır. Ortalama, varyans gibi bireysel piksel değerlerinden elde edilen, pikseller arasındaki uzamsal etkileșimi göz ardı eden birinci-derece istatistiksel öznitelikler yerine daha ayrrt edici özellikleri olan ikinci-derece öznitelikler tercih edilmiştir. GSBM matrisinden yararlanarak bulunan ikinci-derece istatistiksel doku öznitelikleri, yazında sıklıkla yüksek başarım performansı ile kullanılmıştır. Bu çalışmanın odağı, doku sınıflamaya ilişkin en uygun özniteliklerin bulunmasından ziyade elde bulunan özniteliklerin en yüksek sinıflama başarım performansı ile değerlendirilmesi olduğundan farklı öznitelik setlerinin kullanımı üzerine odaklanılmamıștır.

GSBM yöntemi, doku içinde yer alan piksellerin diğer komşu piksellere göre göreceli konumu hakkında bilgi veren istatistiksel bir yaklaşımdır. $p$ farklı piksel değerine sahip $N \times N$ boyutlu bir $I$ görüntüsünden elde edilen $p \times p$ boyutlu birliktelik matrisi $P$, şu şekilde tanımlanmaktadır:

$$
P(i, j)=\sum_{x, y}^{N}\left\{\begin{array}{cc}
1, & \text { ĕger } I(x, y)=i \text { ve } \\
& I\left(x+\Delta_{x}, y+\Delta_{y}\right)=j \\
0, & \text { diğger durumlar }
\end{array}\right.
$$

Burada, $i$ ve $j$ piksel değerleri, $x$ ve $y$ görüntüdeki uzamsal pozisyonlar ve ofset $\left(\Delta_{x}, \Delta_{y}\right)$, ilgilenilen piksel ile komşu pikselleri arasındaki uzaklığı belirtmektedir.

Yazında GSBM'in kullanımı ile çeşitli istatistiksel doku öznitelikleri önerilmiştir [17]. Bu özniteliklerin tamamının kullanımı, hesapsal maliyeti artırdığından ve yapılan nümerik denemelerde sinıflama performansinı doğrusal olarak yukarı çekmediğinden 
dolayı içlerinden üç tanesi öznitelik setinin oluşturulması amacı ile seçilmiştir. Bunlar, GSBM yerel değişimlerini ölçen kontrast $K$, GSBM elemanlarının karelerinin toplamından oluşan açısal ikinci momentin karesi $M$ ve GSBM elemanların dağılımının GSBM köşegenine yakınlığını ölçen homojenlik $H_{o}$ değerleridir. GSBM matrisi $P^{\prime} \operatorname{den} K, M$ ve $H_{o}$ değerlerinin elde edilişi Denklem 24 'de verilmiştir.

$$
\begin{gathered}
K=\sum_{i} \sum_{j}(i-j)^{2} P(i, j) \\
M=\sum_{i} \sum_{j} P(i, j)^{2} \\
H_{o}=\sum_{i} \sum_{j} \frac{1}{1+(i-j)^{2}} P(i, j)
\end{gathered}
$$

\section{3 Önem Tahminleme}

Bu çalışmada KEKK-ÖU yönteminin teksınıf doku tanıma amacı ile kullanımı önerilecektir. Bu çalıșmada geliştirilen yaklaşım, hedef sınıfa ve test sınıfına ilişkin iki olasılık yoğunluk fonksiyonunun oranının kestirimini (/tahminini) temel almaktadır. Test verisine ilişskin dağılım, hedef sınıfına ilișkin dağılıma ne kadar yakınsa önem değeri 1'e yaklaşmakta olduğundan önem değerine göre sinıflama işleminin yapılabileceği öngörülmüştür. Literatürde, bu oran "önem" olarak adlandırılmaktadır ve durağan olmayan uyarlama [18], değişim-noktası tespiti [19], ortak değişinti tahmini [20] gibi farklı veri işleme amaçları için kullanılmaktadır.

Önem fonksiyonunun tahmini için yazında bulunan çalışmalar göz önüne alındığında kullanılabilecek yaklaşımların en doğal ve naif olanının, iki farklı dağılıma ait verilerden olasılık yoğunluk fonksiyonlarını ayrı ayrı tahmin etmek ve daha sonra oranını alarak önemini hesap etmek olduğu görülmektedir. Ancak, olasılık yoğunluk fonksiyonu tahmini özellikle yüksek boyutlu durumlarda zor bir problem olarak bilinmektedir ve tahminlenen dağılımların oranının alınması hatanın yükselmesine neden olmaktadır. Bu nedenle, bu çalışmada yoğunluk olasıllk yoğunluk fonksiyonlarını ayrı ayrı tahmin etmeden önem değerini tahminleyebilen KEKK-ÖU yöntemi [16] tercih edilmiştir.

$\widehat{D} \in R^{d}$ veri tanım kümesi olsun ve $\left\{x_{i}^{t r}\right\}_{i=1}^{n_{t r}}$ eğitim veri örneklerinin, $p_{t r}(x)$ hedef sınıfa ilișkin eğitim yoğunluk dağılımından ve $\left\{x_{j}^{t e}\right\}_{j=1}^{n_{t e}}$ test veri örneklerinin, $p_{t e}(x)$ test yoğunluk dağılımından verilmiş olduğunu kabul edelim. Amaç, önem fonksiyonu $w(x)^{\prime}$ in $\left\{x_{i}^{t r}\right\}_{i=1}^{n_{t r}} \quad$ ve $\quad\left\{x_{j}^{t e}\right\}_{j=1}^{n_{t e}} \quad$ kullanarak tahminini/kestirimini bulmaktır:

$$
w(x)=\frac{p_{t e}(x)}{p_{t r}(x)}
$$

Burada temel kisit, önem $w(x)^{\prime}$ in kestiriminde, yoğunluklar $p_{t r}(x)$ ve $p_{t e}(x)^{\prime}$ in ayrı ayrı tahminlenmesinden kaçınılmasıdır. Önem $w(x)$, doğrusal bir model olarak aşağıda verildiği şekilde modellenebilir.

$$
\widehat{w}(x)=\sum_{l=1}^{b} \alpha_{l} \varphi_{l}(x)
$$

Burada, $\quad \alpha=\left(\alpha_{1}, \alpha_{2}, \ldots, \alpha_{b}\right)^{T}, \quad$ veri örneklerinden öğrenilecek parametreleri,

${ }^{T}$ matris veya vektörün transpozunu, $b$ baz fonksiyonlarının sayısını ve $\left\{\varphi_{l}(x)\right\}_{l=1}^{b}$, baz fonksiyonlarını temsil etmektedir. $\widehat{w}(x)$ modelindeki $\left\{\alpha_{l}\right\}_{l=1}^{b}$ parametreleri Denklem (7) 'de verilen kare hata $J_{0}$ en azlanarak hesap edilebilir.

$$
J_{0}(\alpha)=\frac{1}{2} \int(\widehat{w}(x)-w(x))^{2} p_{t r}(x) d x
$$




$$
\begin{aligned}
& =\frac{1}{2} \int \widehat{w}(x)^{2} p_{t r}(x) d x \\
& -\int_{t r} \widehat{w}(x) w(x) p_{t r}(x) d x \\
& +\frac{1}{2} \int w(x)^{2} p_{t r}(x) d x \\
& =\frac{1}{2} \int \widehat{w}(x)^{2} p_{t r}(x) d x \\
& -\int_{t} \widehat{w}(x) p_{t e}^{(x) d x} \\
& +\frac{1}{2} \int w(x)^{2} p_{t r}(x) d x
\end{aligned}
$$

$$
\begin{gathered}
=\frac{1}{2} \sum_{l, l^{\prime}}^{b} \alpha_{l} \alpha_{l^{\prime}}\left(\frac{1}{n_{t r}} \sum_{i=1}^{n_{t r}} \varphi_{l}\left(x_{i}^{t r}\right) \varphi_{l^{\prime}}\left(x_{i}^{t r}\right)\right. \\
-\sum_{l}^{b} \alpha_{l}\left(\frac{1}{n_{t e}} \sum_{j=1}^{n_{t e}} \varphi_{l}\left(x_{i}^{t e}\right)\right) \\
=\frac{1}{2} \alpha^{T} \widehat{H} \alpha-\widehat{h}^{T} \alpha
\end{gathered}
$$

(9) elde edilir. Burada, $\widehat{H}, b \times b$ boyutlu bir matristir ve $\left(l, l^{\prime}\right)$ 'inci elemanı

$$
\widehat{H}_{l, l^{\prime}}=\frac{1}{n_{t r}} \sum_{i=1}^{n_{t r}} \varphi_{l}\left(x_{i}^{t r}\right) \varphi_{l^{\prime}}\left(x_{i}^{t r}\right)
$$

$\mathrm{J}_{0}(\alpha)^{\prime}$ da ki son terim sabittir ve bu nedenle gözardı edilebilir. İlk iki terimi $J$ ile tanımlayalım. Bu durumda,

$$
\begin{gathered}
J(\alpha)=\frac{1}{2} \int \widehat{w}(x)^{2} p_{t r}^{t r}(x) d x \\
-\int^{t} \widehat{w}(x) p_{t e}(x) d x \\
=\frac{1}{2} \sum_{l, l^{\prime}}^{b} \alpha_{l} \alpha_{l^{\prime}}\left(\int \varphi_{l}(x) \varphi_{l^{\prime}}(x) p_{t r}(x) d\right. \\
-\sum_{l}^{b} \alpha_{l}\left(\int \varphi_{l}(x) p_{t e}(x) d x\right) \\
=\frac{1}{2} \alpha^{T} H \alpha-h^{T} \alpha
\end{gathered}
$$

şeklinde elde edilmektedir. $\hat{h}$ ise,$b$ boyutlu bir vektördür ve l'inci elemanı

$$
\widehat{h}_{l}=\frac{1}{n_{t e}} \sum_{j=1}^{n_{t e}} \varphi_{l}\left(x_{i}^{t e}\right)
$$

'dir. Ĕger negatif değer almama $\left(\alpha \geq 0_{b}\right)$ kısıtı göz ardı edilirse aşağıda Denklem (11) (20) ile verilen kısıtsız en iyileme problemi elde edilir.

$$
\min _{\alpha \in R^{b}}\left[\frac{1}{2} \alpha^{T} \widehat{H} \alpha-\widehat{h}^{T} \alpha+\frac{\lambda}{2} \alpha^{T} \alpha\right]
$$

'dir. Denklem (12)'de, $H, b \times b$ boyutlu bir matristir ve $(l, l)$ 'inci elemanı

$$
H_{l, l^{\prime}}=\int \varphi_{l}(x) \varphi_{l^{\prime}}(x) p_{t r}(x) d x
$$

şeklinde yazılabilir. $h, b$ boyutlu bir vektördür ve l'inci elemanı

$$
h_{l}=\int \varphi_{l}(x) p_{t e}(x) d x
$$

'dir. J'de yer alan beklenenlere, empirik ortalamalar alınarak yaklaşıldığında,

$$
\begin{aligned}
\widehat{J}(\alpha)=\frac{1}{2 n_{t r}} \sum_{i=1}^{n_{t r}} \widehat{w}\left(x_{i}^{t r}\right)^{2} & \\
& -\frac{1}{n_{t e}} \sum_{j=1}^{n_{t e}} \widehat{w}\left(x_{j}^{t e}\right)
\end{aligned}
$$

Burada, $\quad \alpha^{T} \alpha$ terimi karesel düzenlileștirme amacıyla denkleme dahil edilmiştir ve $\lambda(\geq 0)$ düzenlileştirme parametresidir. Denklem (20), kısitsız dışbükey karesel programlama olduğundan dolayı çözüm, analitik olarak

$$
\widetilde{\alpha}(\lambda)=\left(\widehat{H}+\lambda I_{b}\right)^{-1} \widehat{h}
$$

şeklindedir. Burada $I_{b}, b$ boyutlu birim matristir. $\alpha \geq 0_{b}$ negatif olmama kısıtı gözardı edildiğinden bazı öğrenilen parametreler negatif elde edilebilir. $\mathrm{Bu}$ durumu dengeleyebilmek amacı ile

$$
\widehat{\alpha}(\lambda)=\max \left(0_{b}, \widetilde{\alpha}(\lambda)\right)
$$

olarak alınmıştır. Baz fonksiyonu olarak

$$
\varphi_{l}=\exp \left(-\frac{|| x-c_{l} \|^{2}}{2 \sigma^{2}}\right)
$$


şeklinde tanımlanan Gauss fonksiyonu seçilmiștir. $\sigma>0$ Gauss genişliği ve $c_{l}$, $\left\{x_{i}\right\}_{i=1}^{n_{t e}}$ 'den rastgele seçilen Gauss merkezidir.

Önem değeri tahminlemesinde tercih edilen yöntem KEKK-ÖU, çekirdek genişliği $\sigma$ ve düzenlileştirme parametresi $\lambda$ değerlerini birisi-dışarıda çapraz geçerlilik sınaması ile hesapsal karmaşıklık derecesini artırmadan en uygun değere ayarlayabilmektedir.

\section{4 Önerilen Yöntem}

Bölüm 2.3 'de verilen yöntem ile hesaplanan önem değeri, aşağıda verilecek algoritmada kullanılarak doku tanıma gerçekleştirilmiştir. Önerilen yöntem sonucu elde edilen ikili imgede beyaz pikseller hedef sınıfa (ilgilenilen doku) ilișkin bölgeleri temsil ederken siyah pikseller arkaplanı (/aykırı değerleri) temsil etmektedir.

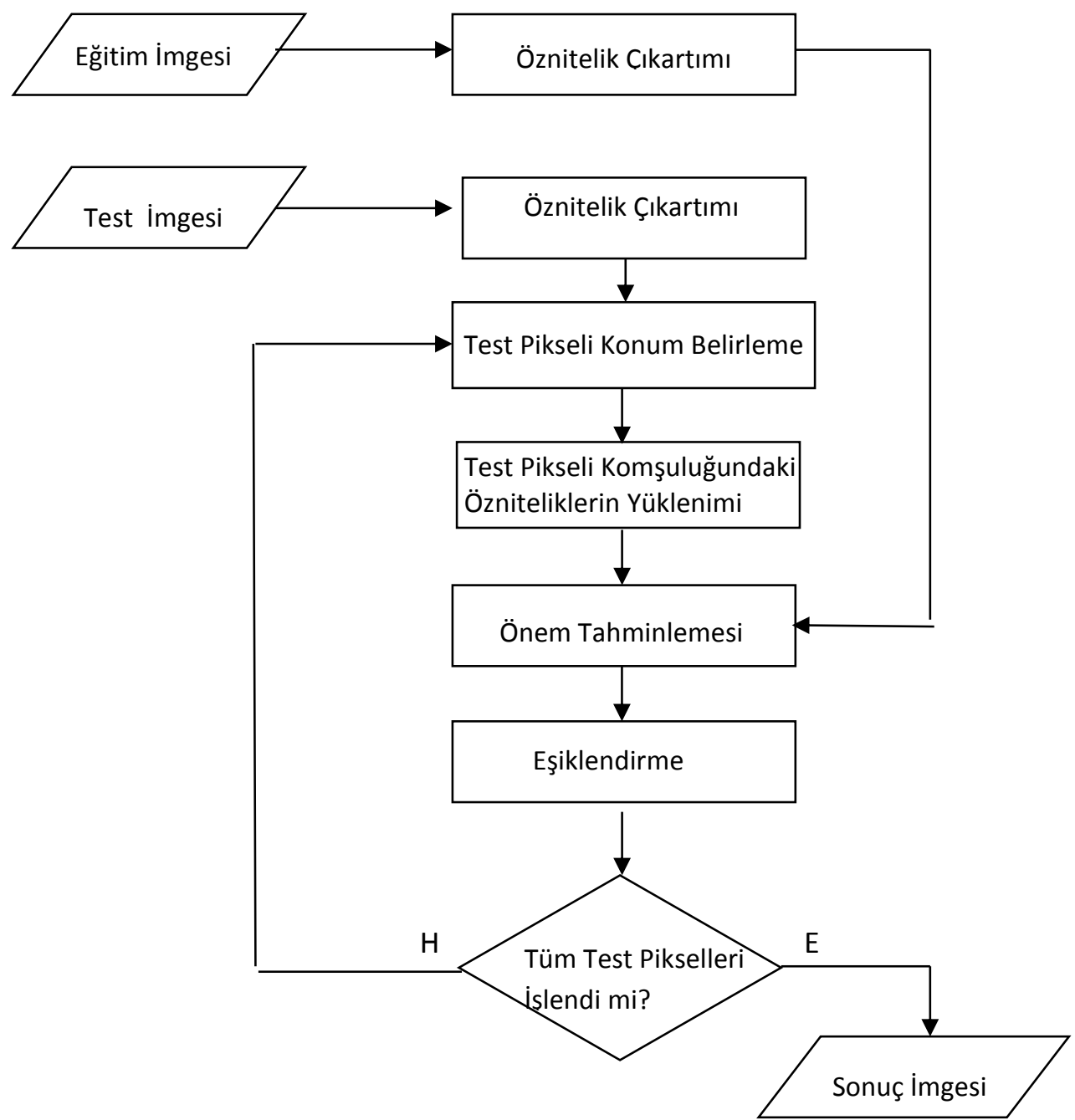

Şekil 1. Önerilen yöntemin akış diyagramı 
İmge I içinde bulunan doku D'yi bulmak için önerilen yöntem şu şekildedir: Öncelikle hedef sinıf eğitim seti oluşturulur. Bunun için hedef doku D 'yi içeren bir alt imgeye ilişkin öznitelikler elde edilir. Daha sonra test görüntüsünde sınıflanmak istenen pikseli merkez alacak șekilde bir pencere seçilir ve bu pencere içindeki verilere ait öznitelikler bulunur. Test verisi ve eğitim verisi kullanılarak önem değeri tahminlenir. Tüm test pikselleri için bu adımlar tekrarlanır. İşlem sonunda, elde edilen önem değerlerine uygun bir eşik değeri bulunur. Eğer önem değeri, eşik değerinden daha yüksekse ilgili pikseli beyaz (/hedef sinıf) olarak değilse siyah (/arkaplan) olarak etiketlenerek ikili sonuç görüntüsü elde edilir. Önerilen algoritmanın akış şeması Şekil 1. 'de verilmiştir

Önerilen yöntemin sonucunu etkileyen parametrelerden bir tanesi seçilen pencere genişliği $n$ 'dir. $n$ değerinin küçük olması, dokuyu temsil eden yoğunluk dağılımının yeterli ş̧ekilde örneklenememesi ile sonuçlanacaktır. $n$ değerinin büyük seçilmesi ise yöntemin hesapsal zamanının artmasına neden olacaktır. Önem tahminlemesinde kullanılan temel baz fonksiyonlarının sayısı $b$, önerilen yöntemin bir başka serbest parametresidir. $b$ değerinin az olması önem fonksiyonunun yeteri kadar baz fonksiyonu ile temsil edilememesine yol açarken bu sayının çok yüksek tutulması komplikasyonu arttırdığından performans üzerinde ters etki yaratabilmektedir. Seçilen eşik değerinin, sonuç ikili imgesi üzerinde etkisi vardır ve farklı yaklaşımlar sonucu hesaplanan eşik değeri, sonuç performansında farklılıklara neden olmaktadır. Ayrıca yanlış onaylanmış cevabı veren tek veya çok az piksel içeren bölgelerin, morfolojik işlemler gibi ek uygulamalar ile yok edilmesi mümkün olmakla birlikte bu çalışmada, doku alanının en doğru şekilde bölütlenmesinden ziyade dokunun varlığının tespiti ile ilgilenildiğinden önerilen yönteme bu tür yaklaşımlar eklenmemiştir. Parametre değişimlerinin sonuç üzerindeki etkileri Bölüm 3'de detaylı olarak incelenmiştir.

\section{Deneysel Sonuçlar}

KEKK-ÖU'nın doku tanıma probleminin çözümündeki etkinliğini test etmek için önerilen yöntem farklı doku örneklerine uygulanmıştır. Çalışmada kullanılan görüntüler, Brodatz Doku verisetinden alınmıştır [21]. Problem Matlab ortamında, 2,0 GHz Çift Çekirdekli Intel İșlemcili, 2 GB RAM'e sahip bir kişisel bilgisayarda gerçeklenmiștir. Ayrıca, elde edilen sonuçlar, yazında sıklıkla tercih edilen Tek-Sınıf Destek Vektör Makinaları yöntemi ile karşılaştırılmıştır.

Önerilen yöntemin performansının değerlendirilebilmesi amacı ile farklı performans ölçütleri kullanılmıştır. Bunlar, Doğru Kabul Oranı (DKO), Doğru Reddetme Oranı (DRO), Kesinlik (KSN), Doğrululuk (DĞR), F-ölçüm ve sınıflama için geçen hesaplama süresi (S) ‘dir.

Önerilen yöntemin başarımının araştırılması amacı ile ilk aşamada yöntemde kullanılan baz fonksiyonlarının sayısı $b$ 'nin performans üzerindeki etkisi incelenmiştir. Öncelikle hedef sınıfa ilişkin örnek pikseller, görüntü üzerinde işaretlenmiş ve ilgili öznitelik eğitim seti oluşturulmuştur. Önerdiğimiz yöntem ile elde edilen önem değerleri Otsu yöntemi [22] ile elde edilen eşik değeri ile karşılaştırılmış ve sonuca göre test pikseli hedef sinıfa veya arkaplan sinifina atanmıștır. KEKK-ÖU yönteminde BirisiDışarıda Çapraz Doğrulama (BDÇD) değeri analitik olarak hesaplanabilmektedir. Bu özelliği nedeni ile BDÇD gerçeklemesi, hesapsal karmaşıklık olarak tek bir çözümün hesaplanması ile aynı dereceye sahiptir. $\mathrm{Bu}$ çalışmada da, bu avantajdan yararlanabilmek amacı ile KEKK_ÖU 
yönteminin düzenlileştirme parametresi $\lambda$ ve Gauss genişliği $\sigma$, BDÇD uygulanarak en optimal sonucu verecek şekilde bulunmuștur. Bulunan $\sigma$ ve $\lambda$ değerleri sırası ile 0,01 ve 0,001 'dir.

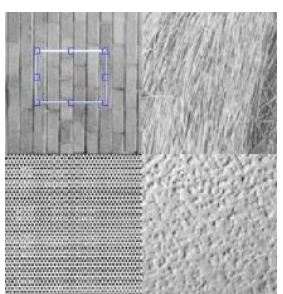

(a)

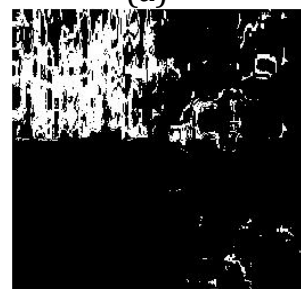

(c)

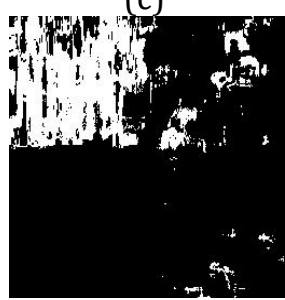

(e)

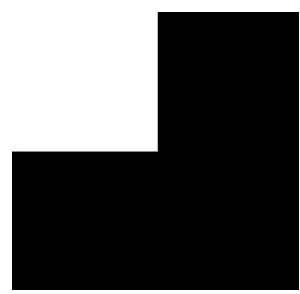

(b)

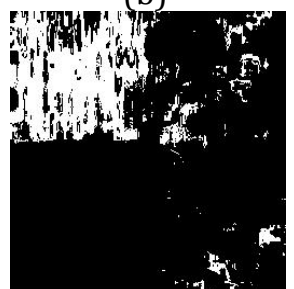

(d)

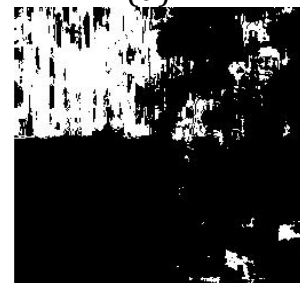

(f)
Şekil 2 (a) Giriş imgesi ve hedef sınıftan seçilen eğitim veriseti , (b) istenen sonuç imgesi, kullanılan baz fonsiyon sayısı (c) $b=50$, (d) $b=100$, (e) $b=150$ ve (f) $b=200$ olduğu durumda elde edilen sonuç imgeleri.

Şekil 2 farklı baz fonksiyon sayıları için TSS'in çıkışlarını göstermektedir. Test verisi için kullanılan pencere genişliği $n$, 10'dur. Şekil 2(a)'da dört farklı dokuyu içeren test giriș imgesi verilmiştir. Ayrica eğitim seti olarak kullanılacak hedef doku bölgesi, giriş imgesi üzerinde sol üst doku içinde kutu içine alınmış alan olarak belirlenmiştir. İstenen sonuç imgesi, sadece sol üst dokuya ilişkin piksel değerlerinde bir (hedef sınıf),diğer piksel bölgelerinde sıfır (hedef dışı sınıf) değeri vermelidir (Şekil 2(b)). Şekil 2(c)-(f), baz fonksiyon sayısının 50, 100, 150 ve 200 olduğu durumlar için elde edilen TSS sonuç imgelerini göstermektedir. Baz fonksiyon sayısı arttıkça hedef sınıf doğru bulma oranları artmaktadır. Bu duruma paralel olarak yanlış kabul değerlerinde de azalış gözlemlenmektedir. Sonuçların daha iyi değerlendirilebilmesi amacı ile hata matrisleri de hesaplanmış ve Şekil 3 'te verilmiștir. Burada, sütunlarda yer alan Kabul ve Ret istenen çıkışları, sütunlarda yer alan Doğru ve Yanlış uygulanan yöntemin bulmuş olduğu çıkış değerlerini temsil etmektedir. Doğru kabul değerleri $b=50$ için 8502, b=100 için 10070, b=150 için 10479 ve b=200 için 11247'dir. En iyi değerin baz fonksiyon sayısının artması ile elde edilebileceği gözlemlenmekle birlikte yapılan deneylerde baz fonksiyon sayısının 200 değerinden daha yüksek değerlere çekilmesi doğru kabul değerlerinde önemli bir değișikliğe yol açmamıştır. Yanlış kabul değerleri $b=50$ için 7882, b=100 için 6314, b=150 için 5905 ve b=200 için 5137'dir. Baz fonksiyon sayısının artması yanlış kabul değerlerinin düşmesine neden olmaktadır. Bununla birlikte, b değerinin artması doğru ret oranlarında da düşüse neden olmaktadır. Sonuçların daha bütüncül incelenebilmesi amacı ile hata matrislerinden elde edilen DKO, DRO, KSN, DĞR ve F-ölçüm değerleri Tablo 1'de verilmiştir. Sonuçlar incelendiğinde, önem tahminlemede kullanılan baz fonksiyon sayısının artması, doğru kabul oranını düşürmekle birlikte doğru ret oranını, kesinliği, doğruluğu ve F-ölçüm değerlerini arttırmaktadır. Örnek olarak F-ölçüm değeri $b=50$ için $0,645, b=100$ 
için 0,708, b=150 için 0,724 ve b=200 için 0,747'dir. Baz fonksiyon sayısının artışı ile hesaplama süresinde de belirgin artışlar oluşmuştur. $b=50,100,150$ ve 200 değerleri için geçen hesaplama süreleri sırası ile $0,758,1,341,1,983$ ve 2,917 saniyedir. Elde edilen sonuçlar, beklenildiği üzere, sınıflama başarımı ve hesaplama süresi arasında bir ödünleşme olduğunu göstermektedir.

\begin{tabular}{|l|l|l|}
\hline & Kabul & Ret \\
\hline Doğru & 8502 & 7882 \\
\hline Yanlıș & 1453 & 47699 \\
\hline
\end{tabular}

(a)

\begin{tabular}{|l|l|l|}
\hline & Kabul & Ret \\
\hline Doğru & 10479 & 5905 \\
\hline Yanlış & 2071 & 47081 \\
\hline
\end{tabular}

(c)

\begin{tabular}{|l|l|l|}
\hline & Kabul & Ret \\
\hline Doğru & 10070 & 6314 \\
\hline Yanlıș & 1961 & 47191 \\
\hline
\end{tabular}

(b)

\begin{tabular}{|l|l|l|}
\hline & Kabul & Ret \\
\hline Doğru & 11247 & 5137 \\
\hline Yanlış & 2476 & 46676 \\
\hline
\end{tabular}

(d)
Şekil 3 Kullanılan baz fonksiyon sayısı (a) $b=50$, (b) $b=100$, (c) $b=150$ ve (d) $b=200$ için elde edilen hata matrisleri.

Tablo 1. Farklı baz fonksiyon sayılarına sahip KEKK_ÖÜ yönteminin performansı

\begin{tabular}{l|clll}
\hline & $b=50$ & $b=100$ & $b=150$ & $b=200$ \\
\hline DKO & 0,854 & 0,837 & 0,831 & 0,819 \\
DRO & 0,858 & 0,881 & 0,888 & 0,900 \\
KSN & 0,518 & 0,614 & 0,639 & 0,686 \\
DĞR & 0,857 & 0,873 & 0,878 & 0,883 \\
F-ölçüm & 0,645 & 0,708 & 0,7224 & 0,747 \\
S (sn) & 0,758 & 1,341 & 1,983 & 2,917
\end{tabular}

Yöntemin farklı pencere genişliklerine gösterdiği tepki, $b=150$ durumu için Şekil 4 'de verilmiştir. Bölüm 2 'de açıklandığı gibi her bir test pikseli için test pikselinin yakın komşuluğundaki piksellere ilişkin öznitelik dağılım fonksiyonunun, hedef sınıf dağılım fonksiyonuna oranı tahminlenmektedir. Beklendiği üzere, dağılım fonksiyonunu temsil edecek veri sayısı arttıkça doğru kabul değeri artmaktadır. Hedef sınıf, Șekil 4(a)'da verilen imgenin sol üst bölgesinde yer alan dokudur. Dolayısı ile istenen sonuç imgesi Şekil 4(b) 'de verildiği gibidir. Pencere genişliği $n=10$ ve $n=20$ için elde edilen sonuç imgeleri Șekil 4(c) ve Şekil 4(d)'de gösterilmiștir. Pencere genişliğinin artmasının, diğer sınıf dokuların hedef sınıftan ayırt edilmesinde etkin bir rolü olduğu görülmektedir. $n=20$ için DKO 1, DRO 0,811, KSN 0,302, DĞR 0,825 ve F-ölçüm 0,464'tür (Tablo 2). Elde edilen sonuçlar, $n=10$ olduğu durumla karşılaştırıldığında DKO oranını, yüksek pencere genișliğinin artırdığ görülmektedir. Diğer ölçütlerde ise azalmaya neden olmuştur. Yoğunluk dağılımlarının hesaplanmasında çok daha fazla sayıda örnek kullanılmasından dolayı hesaplama süresinde belirgin artıșlar olmuș ve süre 2,434 saniyeye ulaşmıştır. KEKK-ÖÜ yönteminin sonuçları, farklı hedef dokular ile de incelenerek yöntemin bașarımı araștırılmıștır. Șekil 5'de hedef doku olarak dört farklı dokudan sol alt bölgede yer alan doku (Şekil 5(a)), hedef sınıf olarak seçilmiş ve kutu içine alınan pikseller eğitim setini olușturmuștur. $n=10$ ve $n=20$ için elde edilen sonuç imgeleri Şekil 5(c) ve Şekil 5(d)'de verilmiștir. Her iki durum için de DKO birdir. F-ölçüm değeri $n=10$ için 0,954 iken $n=20$ için 0,886'dır.

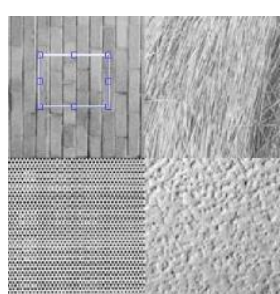

(a)

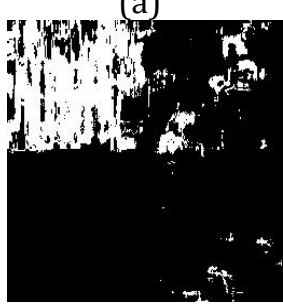

(c)

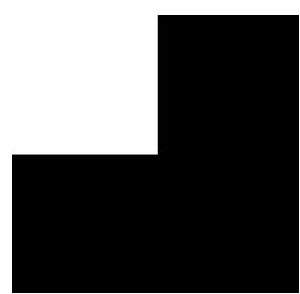

(b)

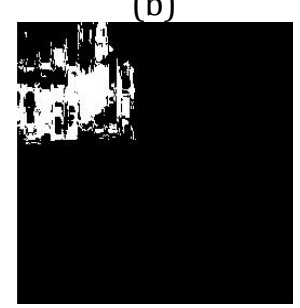

(d)
Şekil 4 (a) Giriș imgesi ve hedef sınıftan seçilen eğitim veriseti , (b) istenen sonuç 
imgesi, test pikseli için kullanılan pencere genişliği (c) $n=10$, (d) $n=20$ için elde edilen sonuç imgeleri.

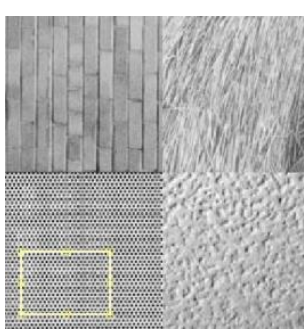

(a)

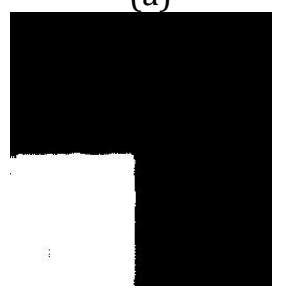

(c)

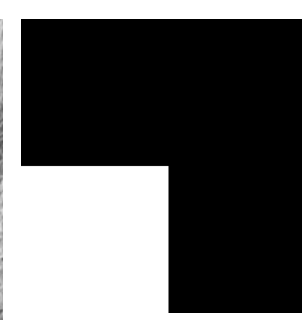

(b)

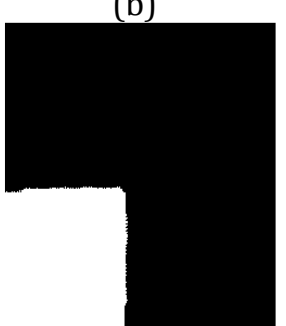

(d)
Şekil 5 (a) Giriș imgesi ve hedef sınıftan seçilen eğitim veriseti , (b) istenen sonuç imgesi, test pikseli için kullanılan pencere genişliği (c) $n=10$, (d) $n=20$ için elde edilen sonuç imgeleri.

Tablo 2. KEKK-ÖÜ ve TS-DVM yöntemlerinin performansları

\begin{tabular}{l|ll|ll}
\hline \multicolumn{2}{c|}{ Şekil 4 } & \multicolumn{2}{c}{ Şekil 5 } \\
\hline \multicolumn{3}{r|}{ KEKK_ÖU } & TS_DVM & KEKK_ÖU TS_DVM \\
\hline DKO & 1 & 1 & 1 & 1 \\
DRO & 0,811 & 0,800 & 0,936 & 0,895 \\
KSN & 0,302 & 0,252 & 0,795 & 0,650 \\
DĞR & 0,825 & 0,813 & 0,948 & 0,912 \\
F-ölçüm & 0,464 & 0,402 & 0,886 & 0,787 \\
S(sn) & 2,434 & 3,355 & 2,216 & 4,744
\end{tabular}

Önerilen tek-sinıf sinıflayıcı KEKK_ÖÜ'nün başarımının değerlendirilmesi amaciyla elde edilen sonuçlar, yazında sıklıkla kullanılagelen ve güçlü bir algoritma olarak kabul gören TS-DVM yönteminin sonuçları ile karşılaştırılmıştır. TS-DVM yönteminde baz fonksiyonu olarak gauss fonksiyonu seçilmiştir. $\mathrm{Bu}$ yöntemin serbest parametreleri olan aykırı değer oranı ve Gauss çekirdek genișliği, ızgara arama yöntemi ile en optimal sonucu verecek şekilde bulunmuştur. Uygulanan aykırı değer oranı 0,1 ve gauss çekirdek genişliği 1'dir. Önerilen yöntem KEKK_ÖÜ ve TS_DVM sonuçları Şekil 4(a) ve Șekil 5(b) de belirtilen hedef dokular için Tablo 2'de verilmiştir. Burada KEKK_ÖÜ için uygulanan pencere genişliği, $n, 20$ ve kullanılan baz fonksiyon sayısı, $b, 150$ 'dir. Her iki farklı hedef sınıf durumu için DKO birdir. Şekil 4(a) da verilen hedef sınıf için KEKK_ÖÜ yönteminin sonuçlarına göre DRO 0,811 , KSN 0,302, DĞR 0,825 ve Fölçüm 0,464'tür. Aynı hedef sınıf için TS_DVM sonuçlarına göre DRO 0,800, KSN 0,252, DĞR 0,813, F-ölçüm 0,464'dür. Sonuçlar, her ölçütte önerilen yöntemin TS_DVM'e göre daha iyi sonuçlar verdiğini göstermektedir. Șekil 5(a) da gösterilen diğer hedef sınıf için de sonuçlar incelenmiş ve doğru reddetme oranı KEKK_ÖÜ için 0,936 TS_DVM için 0,895 olarak, kesinlik KEKK_öÜ için 0,795 TS_DVM için 0,650 olarak, doğruluk KEKK_ÖÜ için 0,948 TS_DVM için 0,787 olarak ve F-ölçüm, KEKK_ÖÜ için 0,936 TS_DVM için 0,895 olarak bulunmuştur. Sonuçlar, bu hedef sınıf için de önerilen yöntemin daha iyi sonuçlar verdiğini göstermektedir. KEKK_ÖÜ yöntemi farklı hedef sinıflar için 2,432 sn ve 2,216 sn sürerken TS_DVM 3,355 ve 4,744 -sn sürmektedir. İki yöntem süre yönünden incelendiğinde önerilen yöntemin daha hızlı olduğunu göstermektedir. Burada belirtmek isteriz ki TS_DVM yönteminin hesaplama süresinde, uygulanan gauss çekirdek genişliğinin otomatik aranması da etkilidir.

\section{Tartışma}

$\mathrm{Bu}$ makalede, iki yoğunluk fonksiyonu arasındaki oran olan önem değerine dayanan bir tek-sınıf sınıflayıcı yöntemi önerilmiştir. Önem değeri hesabında, hedef ve test sınıfı yoğunluk 
fonksiyonlarının ayrı ayrı tahminlenmesinden kaçınılmış ve yüksek boyutlarda da başarılı sonuçlar veren KEKK_ÖU tercih edilmiştir. Önerilen yöntemin başarımı, doku sınıflama probleminde uygulanmiş ve önem tahminlemeye dayalı bir TSS yönteminin kullanışlı olduğu gösterilmiștir. Önerilen yöntemde, önem değeri tahminlemesinde kullanılan baz fonksiyonlarının sayısı ve yoğunluk fonksiyonlarında kullanılan veri sayısının etkin olduğu ve en iyi sonucu verecek şekilde dikkatli bir şekilde seçilmesi gerektiği görülmüştür. Elde edilen sonuçlar, literatürde referans yöntem olarak kullanılan tek-sınıf destek vektör makinaları ile karşılaştırılmıştır. Sonuçlar, önerilen yöntemin daha az hesaplama süresinde daha yüksek tek sınıf sinıflama performansı verdiğini göstermektedir.

Önerilen yöntemin daha da hızlandırılabilmesi için test pikseli komşuluğundaki tüm piksellerin kullanımı yerine k-ortalama benzeri bir öbekleme yöntemi ile veri sayısının azaltılmasının etkin olabileceği düşünülmektedir. Bu konuda ileride yapılabilecek bir incelemenin yanısıra sadece bir test pikseli özelinde dönen önem değeri yerine farklı uzamsal ölçeklerde alınmış test bölgesine ilişkin önem değerlerinin hiyerarşik bir yapı ile incelenmesi de bir sonraki araştırma konuları arasındadır.

\section{Kaynakça}

[1] Tax, D. M.J. 2001. One-Class Classification. TU Delft, Delft University of Technology.

[2] Maglaras, L. A., Jiang, J., Cruz, T. 2014. Integrated OCSVM mechanism for intrusion detection in SCADA systems. Electronics Letters, Cilt: 50(25), s. 1935-1936.

[3] Guerbai, Y., Chibani, Y., Hadjadji, B., 2015. The effective use of the one- class SVM classifier for handwritten signature verification based on writer-independent parameters, Pattern Recognition, Cilt 48, s. 103113.

[4] Guillermo, L.G. , Lucas, C.U., Pablo M.G. 2013. Abrupt Change Detection with One-Class Time-Adaptive Support Vector Machines, Expert Systems with Applications, Cilt 40, s. 7242 7249.

[5] Hyun, J.S., Dong-Hwan, E., Sung-Shick, K., 2005. One-class Support Vector Machines-An Application In Machine Fault Detection and Classification, Computers and Industrial Engineering, Cilt 48, s. 395-408.

[6] Ciesielski, V., Phuong Ha V. 2009, Texture Detection Using Neural Networks Trained on Examples of One Class, s.140-149, Nicholson, A., Li, X. ed. 2009, LNAI 5866, SpringerVerlag Berlin Heidelberg.

[7] Sanchez-Yanez, R.E., Kurmyshev, E.V., Fernandez, A. 2003. One-class texture classifier in the CCR feature space, Pattern Recognition Letters Cilt. 24, s. 1503-1511

[8] Chen, C.H. (Ed.), 2015. Handbook of pattern recognition and computer vision. World Scientific.

[9] Demir, G.K. 2017, A Spectral Graph Theoretical Approach to Oriented Energy Features, International Journal of Pattern Recognition and Artificial Intelligence, Cilt. 31, s. 1755001_1-1755001_27.

[10] Depeursinge, A., Püspöki, Z., Ward, J. P., \& Unser, M. 2017. Steerable wavelet machines (SWM): learning moving frames for texture classification. IEEE Transactions on 
Image Processing, Cilt 26, s. 16261636.

[11] Scholkopf, J., Platt, J., Shawe-Taylor, J., Smola, A., Williamson, R. 2001, Estimating the Support of a HighDimensional Distribution. Neural Computation, Cilt 13, s.1443-1471.

[12]Erfani, S. M., Rajasegarar, S., Karunasekera, S., \& Leckie, C. 2016. High-dimensional and large-scale anomaly detection using a linear oneclass SVM with deep learning. Pattern Recognition, Cilt 58, s. 121-134.

[13] Gondra, I., Heisterkamp, D., Peng, J. 2004, Improving Image Retrieval Performance by Inter-query Learning with One-class Support Vector Machines, Neural Computing and Applications, Cilt 13, s. 130-139

[14] Breunig, M.M., Kriegel,H.P., Ng,R.T., Sander J. 2000, Lof: Identifying Density-Based Local Outliers, ACM Sigmod Record, Cilt 29, s. 93-104.

[15].Hempstalk, K., Frank, E., Witten, I.H., 2008, One-Class Classification by Combining Density and Class Probability Estimation, Daelemans, W., Goethals, B., Morik, K. ed. Machine Learning and Knowledge Discovery in Databases. ECML PKDD 2008. Lecture Notes in Computer Science, Cilt 5211, Springer, Berlin, Heidelberg.

[16] Kanamori, T., Hido, S., Sugiyama, M. 2009, A least-squares approach to direct importance estimation, Machine Learning Research, Cilt 10, s.1391-1445.

[17] Haralick,R.M., Shanmugam, K., Dinstein, I. 1973, Textural Features for Image Classification, IEEE Transactions on Systems, Man and Cybernetics, Cilt 3, s. 610-621.

[18] Hido, S., Tsuboi, Y., Kashima, H., Sugiyama, M., Kanamori, T. 2011, Statistical Outlier Detection Using Direct Density Ratio Estimation, Knowledge and Information Systems, Cilt 26, s. 309-336.

[19] Liu, S., Yamada, M., Collier, N., \& Sugiyama, M. 2013. Change-point detection in time-series data by relative density-ratio estimation. Neural Networks, Cilt 43, s. 72-83.

[20] Balzi, A., Yger, F., \& Sugiyama, M. 2015. Importance-weighted covariance estimation for robust common spatial pattern. Pattern Recognition Letters, Cilt 68, s. 139145 .

[21] Brodatz, P. 1966, Textures: A Photographic Album for Artists and Designers, Dover, Newyork.

[22] Otsu, N. 1979, A Threshold Selection Method from Gray-Level Histograms, IEEE Transaction on Systems Man and Cybernetics, Cilt. 9, s. 62-66. 